\title{
Primary bile acid diarrhoea without an ileal carrier defect: quantification of active bile acid transport across the ileal brush border membrane
}

\author{
A J P van Tilburg, F W M de Rooij, J W O van den Berg, M van Blankenstein
}

\begin{abstract}
Unexplained bile acid malabsorption associated with diarrhoea that responds to cholestyramine was first described in 1973 but convincing evidence of the proposed mechanism - a defective active ileal bile acid transport - has never been substantiated. Active bile acid transport was quantified in vitro using brush border membrane vesicles prepared from terminal ileal biopsy specimens from 10 patients who fulfilled the criteria of idiopathic bile acid diarrhoea. They were recruited from 181 patients with bile acid malabsorption of various causes. Transport was quantified as in vitro $\mathrm{Na}^{+}$dependent bile acid transport (INBAT), expressed as pmol taurocholate/mg brush border membrane protein/15 seconds, and in vitro $\mathrm{Na}^{+}$dependent bile acid local transport capacity (INBALTC), expressed as pmol taurocholate/g ileal biopsy tissue/15 seconds. The lowest INBAT and INBALTC values in the 10 patients with idiopathic bile acid diarrhoea were well above the 10th centile values of a control group of 132 patients. Both INBAT (mean (range) 88 (30136)) and INBALTC (158(85-268)) values were significantly higher in the 10 patients than in the control group (INBAT: mean (range) 63 (1-244), INBALTC: mean (range) 98 (1-408)). Quantification of active ileal bile acid transport in these 10 patients with idiopathic bile acid malabsorption suggests that a genetic (carrier) defect is rare in adults.
\end{abstract}

Increased faecal bile acid loss occurs in most patients with terminal ileal disease and after ileal resection. This is called bile acid malabsorption type $1 .{ }^{12}$ Hess Thaysen and Pedersen described three patients with chronic diarrhoea of unknown aetiology, increased faecal bile acid loss, and a response to cholestyramine treatment. ${ }^{34}$ Several more patients with idiopathic or primary bile acid malabsorption (type 2) have now been described, ${ }^{5-7}$ since determination of bile acid excretion has been facilitated by the introduction of ${ }^{14} \mathrm{C}$ and later ${ }^{75} \mathrm{Se}$ labelled bile acids and the ${ }^{75}$ selenium homocholic acid taurine $\left({ }^{75} \mathrm{SeHCAT}\right)$ test has gained wide use in the analysis of chronic

Various other conditions accompanied by increased faecal bile acid loss (bile acid malabsorption type 3 ) have been reported. These include postcholecystectomy diarrhoea; ${ }^{89}$ postvagotomy diarrhoea; ${ }^{10}$ diabetic diarrhoea; ${ }^{112}$ medullary thyroid carcinoma; ${ }^{13}$ cystic fibrosis; $;{ }^{14}$ is and use of various drugs such as colchicine and neomycin, ${ }^{16}{ }^{17}$ theophylline, ${ }^{18}$ biguanides, ${ }^{19}$ mannitol, ${ }^{20}$ and various laxatives. ${ }^{18}$

The aetiology of primary bile acid malabsorption is unknown. In 1973 Hess Thaysen and Pedersen proposed a genetic defect of active ileal bile acid transport but were unable to confirm this in their (adult) patients. Recently, in three patients with primary bile acid malabsorption, distinct morphological changes were described in terminal ileal biopsy specimens. These changes were crypt hyperplastic villous atrophy, colonic metaplasia, and increased mononuclear cell infiltration of the lamina propria. ${ }^{21}$ The patients also showed evidence of abnormal immune function, as shown by the presence of autoantibodies and complement activation. The authors therefore postulated that the patients had an autoimmune disorder, with the ileum as a target organ, resulting in bile acid malabsorption. These findings have not been confirmed by other authors. Heubi et al reported a defective in vitro ileal bile acid uptake in two boys with lifelong diarrhoea and steatorrhoea who had an ultrastructurally normal terminal ileum. ${ }^{22}$ The technique used in this study, however, which was based on an incubation of whole ileal biopsy tissue in a bile acid containing medium for two minutes, could not discriminate between active absorption, passive absorption, or binding.

We recently described the results of an in vitro assay performed on brush border membrane vesicles derived from terminal ileal biopsy tissue which allowed the selective quantification of active $\mathrm{Na}^{+}$dependent bile acid transport. As a genetic carrier defect could be expected to be present anywhere in the distal ileum, we used this technique to investigate the role of the brush border membrane in primary bile acid malabsorption. Bile acid transport was quantified as in vitro $\mathrm{Na}^{+}$dependent bile acid transport (INBAT) and in vitro $\mathrm{Na}^{+}$dependent bile acid local transport capacity (INBALTC) in brush border membrane vesicles derived from terminal ileal biopsy specimens obtained at colonoscopy with retrograde ileoscopy in 10 patients with bile acid malabsorption of unknown cause. The results were compared with those from a group of 132 patients without disorders known to affect active bile acid transport in the distal ileum. ${ }^{23}$

\section{Methods}

PATIENTS

Ten patients referred to our hospital between 1981 and 1988 for chronic diarrhoea were found to have bile acid malabsorption, defined as $3 \alpha$ diarrhoea. 
TABLE I Clinical data of 10 patients with primary bile acid malabsorption in relation to bile acid excretion

\begin{tabular}{|c|c|c|c|c|c|c|c|c|c|c|}
\hline \multirow[b]{2}{*}{$\begin{array}{l}\text { Patient no, } \\
\text { sex }\end{array}$} & \multirow[b]{2}{*}{$\begin{array}{l}\text { Age } \\
\text { (yrs) }\end{array}$} & \multirow{2}{*}{$\begin{array}{l}\text { Duration (yrs)/ } \\
\text { character of } \\
\text { diarrhoea }\end{array}$} & \multirow{2}{*}{$\begin{array}{l}\text { Faecal } \\
\text { weight } \\
\text { (g/day) }\end{array}$} & \multirow[b]{2}{*}{$\begin{array}{l}\text { FBAL } \\
\text { (mmol/day) }\end{array}$} & \multicolumn{2}{|c|}{${ }^{75} \mathrm{SeHCAT}$} & \multicolumn{3}{|c|}{ Recovery of 25 markers } & \multirow[b]{2}{*}{$\begin{array}{l}\text { Effect of } \\
\text { Chol }\end{array}$} \\
\hline & & & & & $\begin{array}{l}W B R_{50} \\
\text { (days) }\end{array}$ & $\begin{array}{l}F L 4 D \\
(\%)\end{array}$ & Day 1 & Day 2 & Day 3 & \\
\hline $\begin{array}{l}1, \mathrm{~F} \\
2, \mathrm{M} \\
3, \mathrm{M} \\
4, \mathrm{M} \\
5, \mathrm{~F} \\
6, \mathrm{~F} \\
7, \mathrm{~F} \\
8, \mathrm{M} \\
9, \mathrm{M} \\
10, \mathrm{~F}\end{array}$ & $\begin{array}{l}37 \\
39 \\
34 \\
56 \\
38 \\
31 \\
55 \\
55 \\
53 \\
44\end{array}$ & $\begin{array}{l}>7 / \text { Cont } \\
\pm 5 / \text { Int } \\
2 / \text { Int } \\
>5 / \text { Cont } \\
5-10 / \text { Cont } \\
4 / \text { Cont } \\
5-10 / \text { Int } \\
>10 / \text { Cont } \\
>10 / \text { Int } \\
>20 / \text { Cont }\end{array}$ & $\begin{array}{l}290 \\
290 \\
250 \\
\dot{2} \\
280 \\
\vdots \\
270 \\
240 \\
260\end{array}$ & $\begin{array}{l}3 \cdot 3 \\
3 \cdot 7 \\
1 \cdot 5 \\
3 \cdot 2 \\
3 \cdot 3 \\
3 \cdot 3 \\
1 \cdot 3 \\
1 \cdot 8 \\
2 \cdot 2 \\
2 \cdot 7\end{array}$ & $\begin{array}{l}1 \cdot 3 \\
1 \cdot 1 \\
1.6 \\
1.0 \\
0 \cdot 1 \\
1.5 \\
1.7 \\
1.8 \\
2 \cdot 1 \\
1.2\end{array}$ & $\begin{array}{l}79 \\
83 \\
77 \\
96 \\
99 \\
85 \\
77 \\
78 \\
75 \\
89\end{array}$ & $\begin{array}{r}23 \\
24 \\
7 \\
\cdot \\
\cdot 7 \\
0 \\
\dot{0} \\
20\end{array}$ & $\begin{array}{l}2 \\
0 \\
18 \\
\vdots \\
\\
18 \\
\\
\\
4\end{array}$ & $\begin{array}{l}0 \\
1 \\
0 \\
\dot{.} \\
\dot{0} \\
\dot{0} \\
\dot{0}\end{array}$ & $\begin{array}{l}++ \\
+ \\
+ \\
+ \\
++ \\
+ \\
++ \\
+ \\
+ \\
+\end{array}$ \\
\hline
\end{tabular}

Chol $=$ cholestyramine; $+=$ marked response; $++=$ complete response; $\bullet=$ not done. $\mathrm{FBAL}=$ faecal bile acid loss $($ normal $<1 \cdot 2 \mathrm{mmol} /$ day), $\mathrm{WBR}_{\mathrm{so}}=$ whole body retention half life (normal $>2 \cdot 8$ day, abnormal $<1.8$ day), FL4D: fractional loss in four days (normal $<58 \%$, abnormal $>72 \%$, Cont $=$ continuous, Int $=$ intermittent

hydroxy bile acids $\geq 1 \cdot 2 \mathrm{mmol} /$ day, ${ }^{24-27}$ for which extensive analysis failed to show a cause. There was no history of food intolerance, appreciable weight loss, alcohol abuse, or use of laxatives or other medication possibly related to the diarrhoea. Routine blood tests including erythrocyte sedimentation rate, full blood count, creatinine, urea, electrolytes, total protein, albumen, bilirubin, alkaline phosphatase, alanine aminotransferase, and glucose were normal.

Patient characteristics, the duration and nature of the diarrhoea, faecal weight, faecal bile acid excretion, and the ${ }^{75} \mathrm{SeHCAT}$ test results, including recovery of radio-opaque markers administered to five patients are presented in Table I. Simultaneous administration of these markers with the ${ }^{75} \mathrm{SeHCAT}$ dose as a control on the accuracy of faecal collection was routinely performed from 1983 onwards. The age and sex distribution of the 10 patients (mean (SD) age 44 (9) years, men:women 1.0) was not different from that of the group of 132 control patients (mean (SD) age 39 (15) years, men:women 0.69). All patients were thoroughly investigated and other causes of diarrhoea were excluded. Results of the investigations performed to determine the cause of the diarrhoea are presented in Table II. Small bowel $x$ rays, colonoscopy with retrograde ileoscopy, and microscopy of terminal ileal biopsy specimens were normal in every patient.

CONTROL GROUP

INBAT values of 132 patients undergoing colonoscopy for conditions not associated with altered active ileal bile acid transport ${ }^{23}$ were used as control values. INBAT values of normal subjects were not available because of the invasive nature of colonoscopy with terminal ileal biopsy.

\section{CHEMICAL BILE ACID ANALYSIS}

Total $3 \alpha$-hydroxy bile acids were determined enzymatically in duplicate in pooled faeces, collected over four or five days. ${ }^{24-26}$

\section{BIOPSY PROCEDURE}

In all 10 patients, a colonoscopy with retrograde ileoscopy was performed. The terminal ileum was endoscopically normal in all patients. Biopsy specimens were taken $5-10 \mathrm{~cm}$ proximal to the ileocoecal valve for light microscopy, and five additional specimens $(25-50 \mathrm{mg}$ ) were directly frozen for bile acid transport studies.

\section{INBAT DETERMINATIONS}

Determination of active bile acid transport, quantified as INBAT, was performed as described in detail previously. ${ }^{23}$ The two main steps of the procedure are the isolation of brush border membrane vesicles and bile acid transport measurements in the isolated vesicles. These steps will be briefly described below.

BRUSH BORDER MEMBRANE VESICLE ISOLATION Frozen ileal biopsy specimens, thawed in iso-

TABLE II Laboratory investigations related to the exclusion criteria for secondary bile acid malabsorption

\begin{tabular}{|c|c|c|c|c|c|c|c|c|c|c|c|c|c|}
\hline \multirow[b]{3}{*}{ Patient no, sex } & \multirow{2}{*}{\multicolumn{2}{|c|}{ Blood }} & \multirow{2}{*}{\multicolumn{2}{|c|}{ Urine }} & \multicolumn{5}{|c|}{ Faeces } & & & & \multirow{3}{*}{$\begin{array}{l}\text { Jejunal } \\
\text { biopsy } \\
\text { specimen }\end{array}$} \\
\hline & & & & & \multicolumn{3}{|c|}{ Biochem } & \multicolumn{2}{|c|}{ Microb } & \multicolumn{3}{|c|}{ Intestinal function test } & \\
\hline & $T_{4}$ & Vit & 5-HIAA & $\operatorname{Lax}$ & Fat & $\alpha-c h$ & $O b$ & Cult & Par & $L B$ & $S T$ & $G C$ & \\
\hline $1, \mathrm{~F}$ & $\mathrm{n}$ & $\mathrm{n}$ & $\mathrm{n}$ & - & $\mathrm{n}$ & $\mathrm{n}$ & - & - & - & $\mathrm{n}$ & - & $\mathrm{n}$ & $\mathrm{n}$ \\
\hline $2, M$ & $\mathrm{n}$ & • & • & . & • & n & - & - & • & - & • & $\mathrm{n}$ & \\
\hline $3, M$ & $\mathrm{n}$ & $\mathrm{n}$ & • & - & - & $\mathrm{n}$ & • & - & - & - & - & . & $\mathrm{n}^{\star}$ \\
\hline $4, M$ & . & • & - & • & - & •. & • & - & - & $\mathrm{n}$ & - & - & $\mathrm{n}^{\star}$ \\
\hline $5, F$ & $\mathrm{n}$ & $\mathrm{n}$ & - & - & - & - & - & - & • & - & • & • & \\
\hline $6, F$ & $\mathrm{n}$ & $\mathrm{n}$ & $\mathrm{n}$ & • & • & - & • & • & - & $\mathrm{n}$ & $\mathrm{n}$ & $\mathrm{n}$ & $\mathrm{n}$ \\
\hline $7, F$ & . & - & - & • & $\mathrm{n}$ & $\mathrm{n}$ & - & - & - & $\mathrm{n}$ & • & - & $\mathrm{n}^{\star}$ \\
\hline $8, M$ & . & . & • & • & • & . & - & - & . & • & • & • & \\
\hline $9, M$ & . & $\mathrm{n}$ & • & . & $\mathrm{n}$ & • & - & - & - & • & $\mathrm{n}$ & $\mathrm{n}$ & \\
\hline $10, \mathrm{~F}$ & $\mathrm{n}$ & $\mathrm{n}$ & $\mathrm{n}$ & - & $\mathrm{n}$ & $\mathrm{n}$ & - & - & - & $\mathrm{n}$ & • & $\mathrm{n}$ & $\mathrm{n}^{\star}$ \\
\hline
\end{tabular}

$\mathrm{n}=$ normal result, $-=$ negative result, $\bullet=$ not done.

$\mathrm{Vit}=$ serum vitamin concentrations ( folic acid, vit $\mathrm{B}_{12}$, iron, vit $\mathrm{D}_{3}$, and vit $\left.\mathrm{A}\right) ; \mathrm{Lax}=$ laxatives, Fat $=$ fat excretion on a diet containing 70 $\mathrm{g}$ fat $(\mathrm{n}<7 \mathrm{~g})$; Cult = culture for Salmonella, Shigella, Yersinia, Campylobacter; Par = repeated microscopic examination for parasites; $\alpha$-ch $=\alpha$-chymotrypsin; $\mathrm{Ob}=$ occult blood; $\mathrm{LB}=\mathrm{H}_{2}$-breath test after $50 \mathrm{~g}$ lactose; $\mathrm{ST}=\mathrm{Schilling}$ test, $\mathrm{GC}={ }^{44} \mathrm{C}$-glycocholate breath test. ^Including establishment of normal disaccharidase activities. 
tonic buffer, were disrupted using a Vibro mixer. After addition of $\mathrm{MgCl}_{2}$ the suspension was centrifuged twice at $500 \mathrm{~g}$. The two combined supernatant fractions were then centrifuged at $27000 \mathrm{~g}$ to spin down the brush border membrane vesicles, and the pellet was resuspended in buffer.

\section{TRANSPORT MEASUREMENTS}

Incubation of the brush border membrane vesicle suspension was performed with a transport buffer containing $4 \mu \mathrm{M}{ }^{3} \mathrm{H}(\mathrm{G})$-taurocholate in the presence of a $108 \mathrm{mmol} / 1 \mathrm{Na}^{+}$gradient. Incubation was stopped by addition of samples of the incubation mixture at fixed time intervals (after 15, 30, and 45 seconds) to ice cold lithocholate saturated stop buffer. Samples were filtered and washed four times with the same stop buffer. Radioactivity on the filter was measured in a liquid scintillation counter and corrected for non-specific binding. The increase in TC uptake between 15 and 30 seconds was used as an uptake parameter, combining uptake quantification, minimal non-specific binding, and a low intraassay variation. INBAT was expressed as pmol taurocholate/mg brush border membrane protein/15 seconds as described previously. ${ }^{23}$

The bile acid transport capacity of the ileal tissue (INBALTC), which is not represented by the calculated INBAT values, was determined by quantifying taurocholate uptake velocity per unit of ileal biopsy tissue (and not per unit brush border membrane vesicle protein). INBALTC could therefore be calculated easily from INBAT (INBALTC $=$ INBAT $\times$ brush border membrane vesicle yield) and was expressed as pmol taurocholate/g ileal biopsy tissue/15 seconds.

\section{CHOLESTYRAMINE TREATMENT}

All patients were treated with cholestyramine. In general, the starting dose was $2 \mathrm{~g}$ twice daily, and the dose was increased to $4 \mathrm{~g}$ three times a day depending on its effect and acceptance by the patients. All patients reported either a considerable decrease in defaecation frequency and improvement in the consistency of stools or a return to normal of defaecation, and even constipation (scored as marked or complete response in Table I).

TABLE III Active ileal bile acid transport parameters and brush border membrane vesicle $(B B M V)$ yield found in patients with primary bile acid malabsorption $(n=10)$ compared with control subjects $(n=132)$

\begin{tabular}{llll}
\hline Patient no, sex & $\begin{array}{l}\text { INBAT } \\
\text { (pmol/mg prot) }\end{array}$ & $\begin{array}{l}\text { INBALTC } \\
\text { (pmol/g tissue) }\end{array}$ & $\begin{array}{l}\text { BBMVyield } \\
\text { (mg prot/g tissue) }\end{array}$ \\
\hline $1, \mathrm{~F}$ & 85 & 183 & $2 \cdot 15$ \\
$2, \mathrm{M}$ & 30 & 229 & $7 \cdot 63$ \\
$3, \mathrm{M}$ & 74 & 268 & $3 \cdot 62$ \\
$4, \mathrm{M}$ & 43 & 117 & $2 \cdot 71$ \\
$5, \mathrm{~F}$ & 111 & 109 & $0 \cdot 98$ \\
$6, \mathrm{~F}$ & 40 & 120 & $2 \cdot 99$ \\
$7, \mathrm{~F}$ & 136 & 91 & $0 \cdot 67$ \\
$8, \mathrm{M}$ & 135 & 134 & $0 \cdot 99$ \\
$9, \mathrm{M}$ & 117 & 243 & $2 \cdot 08$ \\
$10, \mathrm{~F}$ & 112 & 85 & $0 \cdot 76$ \\
Patients mean (range) & $88(30-136)$ & $158(85-268)$ & $2 \cdot 46(0 \cdot 67-7 \cdot 63)$ \\
Control mean (range) & $63(1-244)$ & $98(1-408)$ & $1 \cdot 69(0 \cdot 45-7 \cdot 61)$ \\
\hline
\end{tabular}

INBAT $=$ in vitro $\mathrm{Na}^{+}$dependent bile acid transport (pmol taurocholate uptake/mg brush border membrane protein $/ 15$ seconds).

INBAL TC $=$ in vitro $\mathrm{Na}^{+}$dependent bile acid local transport capacity (pmol taurocholate uptake/g ileal biopsy tissue/15 seconds).

\section{Results}

Bile acid malabsorption was considered to be present when total faecal bile acid excretion was $\geq 1 \cdot 2 \mathrm{mmol} /$ day. ${ }^{24-27}$ The ${ }^{75} \mathrm{SeHCAT}$ whole body retention half life was abnormal $(<1.8$ days $)$ in eight and equivocal (1.8-2.8 days) in two patients, while the fractional ${ }^{75} \mathrm{SeHCAT}$ loss after four days was abnormal $(>72 \%)$ in all patients. The five patients given radio-opaque markers excreted virtually all their markers within 48 hours. In a sixth patient (no 10) carmine red was found in the faeces 21 hours after administration. The results of active bile acid transport studies in our patients are presented in Table III and compared with the transport values obtained in control subjects. In none of the patients were values suggestive of a transport defect found. The lowest individual values found for INBAT and INBALTC corresponded with the 19th and 52nd centiles respectively of the range of INBAT and INBALTC values found in the control group. Moreover, mean INBAT $(p<0.05)$ as well as mean INBALTC $(p<0.05)$ were significantly increased (Wilcoxon signed rank test) compared with values in the control patients. The brush border membrane vesicle yield in the 10 patients with idiopathic bile acid malabsorption did not differ significantly from that in the control group.

\section{Discussion}

Primary bile acid malabsorption, as described by Hess Thaysen and Pedersen in 1973 and 1976, ${ }^{3+}$ is characterised by chronic diarrhoea with increased bile acid loss that is not caused by any of the conditions known to be associated with abnormal bile acid loss and which responds to cholestyramine. Supplying bile acid binding agents such as cholestyramine is an effective antidiarrhoeal treatment in most conditions associated with bile acid malabsorption. A lack of response to cholestyramine, by definition, excludes bile acid malabsorption as the cause of the diarrhoea, but not the presence of increased bile acid excretion. ${ }^{28} \mathrm{~A}$ positive response, however, provides no information about the cause of bile acid malabsorption. As dihydroxy bile acids can induce electrolyte and water secretion by increasing cyclic adenosine monophosphate, ${ }^{29} 30$ measuring faecal aqueous dihydroxy bile acid concentrations can provide additional information about the role of bile acids in the aetiology of the diarrhoea. ${ }^{31}$ These measurements, however, are technically more difficult to perform and may not reflect the actual concentrations in the proximal colon as water and bile acid absorption are different processes and bacterial dehydroxylation continues after defaecation.

Merrick et $a l^{s}$ suggested that primary bile acid malabsorption is probably not as rare as originally thought. ${ }^{34}$ After seven years of evaluating almost 200 patients with bile acid malabsorption we encountered 10 patients who fulfilled the criteria of primary bile acid malabsorption. In none of these patients were histological abnormalities seen in terminal ileal biopsy specimens, distinguishing them from the three patients reported by Popovic et al..$^{21}$ In our opinion their three patients described do not strictly fulfil Hess 
Thaysen and Pedersen's criteria ${ }^{4}$ and should, in fact, be labelled as suffering from type I bile acid malabsorption as their ileal biopsy specimens were morphologically abnormal.

Hess Thaysen and Pedersen proposed a genetic defect in active bile acid transport as the cause of the unexplained bile acid malabsorption in their patients. Active bile acid transport in the ileum is a $\mathrm{Na}^{+}$dependent process which can be seen and quantified in brush border membrane vesicles derived from ileal biopsy tissue..$^{23}{ }^{32} \mathrm{We}$ did not find defective active ileal bile acid transport in any of our patients. In fact, if anything, active bile acid transport, quantified as INBAT and INBALTC, was increased compared with that in the control group. These findings confirm earlier results in eight patients with bile acid losing diarrhoea of various causes. ${ }^{23}$ The present results support our hypothesis that active bile acid transport is regulated by the availability of bile acids to the ileal enterocytes. ${ }^{23}$ As a defect in active bile acid transport cannot be shown, the aetiology of primary bile acid malabsorption remains unclear. The net amount of bile acids escaping ileal reabsorption is probably dependent on the amount and concentration of bile acids entering the terminal ileum, the presence of other intraluminal contents such as fibre ${ }^{33}$ non-absorbed fat ${ }^{34}$ the intraluminal $\mathrm{pH},{ }^{35}$ the frequency of enterohepatic cycling, the ileal transit time ${ }^{20}$ (availability factors), and the number of bile acid carriers per ileal surface area and the total ileal surface containing these carriers (capacity factors). Although no information is available on the length of distal ileum capable of active bile acid transport in primary bile acid malabsorption, it seems unlikely that this segment is effectively shorter in affected patients than in normal subjects. No data are available on the composition and size of the bile acid pool in this condition, which could in theory be altered, leading to higher concentrations of dihydroxy bile acids in the colon.

The most likely explanation for the bile acid malabsorption in these patients seems to be motor disturbances of the ileum resulting in an extremely short ileal transit time which does not allow time for normal reabsorption. ${ }^{728}$ The oroanal transit time data, available in six of our patients, largely reflect a rapid colonic transit, as found in bile acid malabsorption of other causes by various authors, ${ }^{737}$ and do not allow conclusions on the ileal transit time, which was not measured as it was not the subject of this study.

Primary bile acid malabsorption based on a defect in active ileal bile acid transport, if it exists in adults, is probably very rare.

1 Fromm H, Farivar H, McJunkin B. Type 3 bile acid malabsorption and diarrhoea. Evidence for a new clinical entity. Gastroenterology 1977; 72: 1060A

2 Fromm $\mathrm{H}$, Malavolti M. Bile acid-induced diarrhea. Clinics in Gastroenterology 1986; 15: 567-82.

3 Hess Thaysen E, Pedersen L. Diarrhoea associated with idiopathic bile acid malabsorption: fact or fantasy? Danish Med Bulletin 1973; 20: 174-7.

4 Hess Thaysen E, Pedersen L. Idiopathic bile acid catharsis. Gut 1976; 17: 965-70.

5 Merrick MV, Eastwood MA, Ford MJ. Is bile acid malabsorption underdiagnosed? An evaluation of accuracy of diagnosis by measurement of SeHCAT retention. BMF 1985; 290: $665-8$.

6 Hess Thaysen E. Idiopathic bile acid diarrhoea reconsidered. Scand F Gastroenterol 1985; 20: 452-6.

7 Schiller LR, Hogan RB, Morawski SG, et al. Studies of the prevalence and significance of radiolabelled bile acid malabsorption in a group of patients with idiopathic chronic diarrhea. Gastroenterology 1987; 92: 151-60.

8 Hutcheon DF, Bayless TM, Gadacz TR. Postcholecystectomy diarrhea. FAMA 1979; 241: 823-4.

9 Fromm H, Tunuguntla AK, Malavolti M, Sherman C, Ceryak $\mathrm{S}$. Absence of a significant role of bile acids in diarrhea of a heterogenous group of postcholecystectomy patients. Dig Dis Sci 1987; 32: 33-44.

10 Blake G, Kennedy TL, McKelvey STD. Bile acids and postvagotomy diarrhoea. BrF Surg 1983; 70: 177-9.

11 Molloy A, Tomkin GH. Altered bile in diabetic diarrhoea. $B M \mathcal{F}$ 1978; ii: 1462-3.

12 Scarpello JH, Hague RV, Cullen DR, Sladen GE. The ${ }^{14} \mathrm{C}$ glyco-cholate test in diabetic diarrhoea. $B M \mathcal{F} 1976$; ii: 673-5.

13 van Blankenstein $M$. Faecal bile acid radioactivity, a sensitive and relatively simple test for ileal dysfunction. Neth $\mathcal{F}$ Med 1977; 20: 248-52.

14 Weber AM, Roy CC, Chartrand L, et al. Relationship between bile acid malabsorption and pancreatic insufficiency in cystic fibrosis. Gut 1976; 17: 295-9.

15 Fondacaro JD, Heubi JE, Kellogg FW. Intestinal bile acid malabsorption in cystic fibrosis: a primary mucosal cel defect. Pediatr Res 1982; 16: 494-8.

16 Rubulis A, Rubert M, Faloon WW. Cholesterol lowering, fecal bile acid, and sterol changes during neomycin and colchicine. Am 7 Clin Nutr 1970; 23: 1251-9.

17 Race TF, Paes IC, Faloon WW. Intestinal malabsorption induced by oral colchicine. Comparison with neomycin and cathartic agents. Am F Med Sci 1970; 259: 32-41.

18 Orholm M, Pedersen O, Arnfred T, Rödbro P, Thaysen EH Evaluation of the applicability of the SeHCAT test in the investigation of patients with diarrhoea. Scand $\mathcal{F}$ Gastroenterol 1988; 23: 113-7.

19 Caspary WF, Zavada I, Reimold WV, Emrich D, Willms B. Increased deconjugation of bile acids and vitamin $\mathbf{B}_{12} \mathrm{ma}$ absorption in diabetics on treatment with biguanides. In Paumgartner P, Stiehl A, eds. Bile acid metabolism in health and disease. Lancaster: MTP Press, 1977: 271-284.

20 Meihof WE, Kern F Jr. Bile salt malabsorption in regional ileitis, ileal resection and mannitol induced diarrhoea. $\mathcal{F} \mathrm{Clin}$ Invest 1968; 47: 261-7.

21 Popovic OS, Kostic KM, Milovic VB, et al. Primary bile acid malabsorption. Histologic and immunologic studies in three patients. Gastroenterology 1987; 92: 1851-8.

22 Heubi JE, Balistreri WF, Fondacaro JD, Partin JC, Schubert WK. Primary bile acid malabsorption: defective in vitro ilea active bile acid transport. Gastroenterology 1982; 83: 804-11.

23 Van Tilburg AJP, de Rooij FWM, van Blankenstein $M$, van den Berg JWO, Bosman-Jacobs EP. $\mathrm{Na}^{+}$-dependent bile acid transport in the ileum: the balance between diarrhea and constipation. Gastroenterology 1990; 98: 25-32.

24 Grundy SM, Ahrens Jr EH, Miettinen TA. Quantitative isolation and gas-liquid chromatographic analysis of total fecal bile acids. $f$ Lipid Res 1965; 6: 397-410

25 De Wael J, Raaymakers CE, Endeman HJ. Simplified quantitative determination of total fecal bile acids. Clin Chim Acto 1977; 79: 465-70.

26 Malchow-Möller A, Arffmann S, Larusso NF, Krag E. Enzymatic determination of total $3 \alpha$-hydroxy bile acids in faeces. Scand 7 Gastroenterol 1982; 17: 331-3.

27 Tougaard L, Giese B, Höjlund Pedersen B, Binder V. Bile acid metabolism in patients with Crohn's disease in termina ileum. Scand 7 Gastroenterol 1986; 21 : 627-33.

28 Merrick MV. Bile acid malabsorption. Dig Dis 1988; 6: 159-

29 Binder HJ, Filburn C, Volpe BT. Bile salt alteration of colonic electrolyte transport: role of cyclic adenosine monophosphate. Gastroenterology 1975; 68: 503-8.

30 Conley DR, Coyne MJ, Bonorris GG, Chung A, Schoenfield L. Bile acid stimulation of cyclase and secretion in the rabbit Dig Dis Sci 1976; 21: 453-8

31 McJunkin B, Fromm H, Sarva RP, Amin P. Factors in the mechanism of diarrhea in bile acid malabsorption: fecal pH a key determinant. Gastroenterology 1981; 80: 1454-64.

32 de Rooij FWM, van den Berg JWO, Sinaasappel M, bosmanJacobs EP, Touw-Blommestijn AC. Bile acid malabsorption in cystic fibrosis; membrane vesicles, a tool for revealing the role of the ileal brush border membrane. Acta Paed Scand 1984; Suppl 317: 28-30.

33 Stanley MM, Paul D, Gacke D, Murphy J. Effects of cholestyramine, metamucil, and cellulose on fecal bile acid cholestyramine, metamucil, and cellulose on fecal bile

34 Cummings JH, Wiggins HS, Jenkins DJA et al. Influence of diets high and low in animal fat on bowel habit, gastrointestinal transit time, fecal microflora, bile acid, and fat excretion. f Clin Invest 1978; 61: 953-63.

35 Aldini R, Roda A, Festi D, et al. Bile acid malabsorption and bile acid diarrhea in intestinal resection. Dig Dis Sci 1982 27: 495-502.

36 Heaton KW. Functional diarrhoea: the acid test. $B M F 1985$ 290: 1298-9.

37 Fromm H, Thomas PJ, Hofmann AF. Sensitivity and specificity in tests of distal ileal function: prospective comparison of bile acid and vitamin $B_{12}$ absorption in ileal resection patients. Gastroenterology 1973; 64: 1077-90. 